\title{
Frozen elephant trunk technique: Ready to get back to the future?
}

\author{
Davide Pacini, MD, PhD, Giacomo Murana, MD, and Luca Di Marco, MD, PhD
}

\footnotetext{
From the Cardiac Surgery Unit, Cardio-Thoraco-Vascular Department, S. Orsola Hospital, University of Bologna, Bologna, Italy.

Disclosures: Authors have nothing to disclose with regard to commercial support.

Received for publication April 15, 2018; accepted for publication April 16, 2018; available ahead of print June 5 , 2018.

Address for reprints: Davide Pacini, MD, PhD, Cardiac Surgery Unit, Cardio-Thoraco-Vascular Department,

S. Orsola Hospital, University of Bologna, Bologna, Italy (E-mail: davide.pacini@unibo.it).

J Thorac Cardiovasc Surg 2018;156:e79-80

$0022-5223 / \$ 36.00$

Copyright (c) 2018 by The American Association for Thoracic Surgery

https://doi.org/10.1016/j.jtcvs.2018.04.071
}

The frozen elephant trunk (FET) technique has been introduced to simplify the treatment of complex thoracic aortic diseases. Through the years, the technique has gained popularity, and it has been subject of modifications to make the procedure easier and to shorten circulatory arrest time. ${ }^{1,2}$ The management of the left subclavian artery (LSA), however, has remained one of the technique's main drawbacks. To solve this problem, extra-anatomic bypasses and others forms of LSA revascularization have been proposed. ${ }^{3}$ In our Bologna hospital, in patients whose LSA is hard to reach, we reimplant it with the GORE hybrid vascular graft (W.L. Gore \& Associates, Newark, Del), which allows us to perform a sutureless endoluminal anastomosis. ${ }^{4}$ Others have proposed a fenestrated FET, in which a hole is manually created in the stent portion of the graft and a covered stent is then released inside the LSA to seal the artery at the time of surgery. ${ }^{5}$

In this issue of the Journal, Okamura and colleagues ${ }^{6}$ have proposed a modification to further simplify the FET technique further in cases of acute type A aortic dissection. In a 3-step procedure, the Japanese team have deployed the hybrid prosthesis in the descending thoracic aorta, manually created a $10-\mathrm{mm}$ hole into the graft to accommodate the ostium of the LSA, and, finally, reconstructed the remaining arch with separate reimplantation of the arch vessels. These new and interesting insights from Okamura and colleagues ${ }^{6}$ could be summarized as follows:

- Initially, a preassembled hybrid graft was used, and it therefore was possible to preserve the stent graft's integrity, because the fenestration was performed outside the nitinol frame in the proximal Dacron polyester fabric portion. In this way, the radial forces generated by the stent graft are not hampered from their sealing function.

- Later, a newer-generation hybrid prosthesis was used. Unlike other open stent grafts, the Frozenix J Graft (Japan Lifeline Co, Ltd, Tokyo, Japan) has a unique double-layered oval-shaped nitinol stent that easily conforms to the curvature of the aorta.

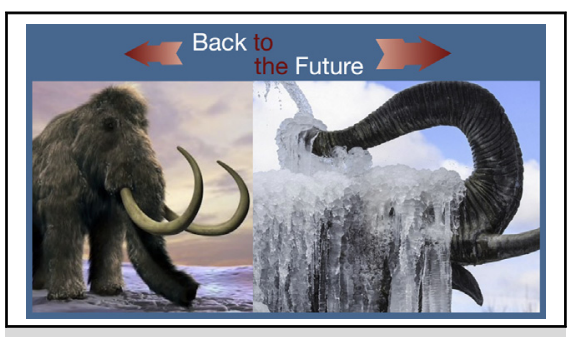

The advancement of the frozen elephant trunk technique.

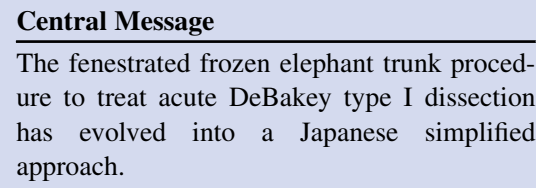

See Article page e75.
- Finally, in what is the key passage of the operation, the LSA was not stented at the time of surgery. Unlike in the previous fenestrated FET versions, the stented part is not overriding the LSA, which had exposed it to an increased risk of type 2 endoleak (from the fenestration). It is too early, however, to anticipate whether the advancements proposed on the modified fenestrated FET, successfully presented Okamura and colleagues, ${ }^{6}$ would be able to combat endoleak formation around the LSA and promote positive remodeling of the treated segment. At the moment, it is possible only to argue that simplification of FET with the introduction of new devices, or with their modification, contributed to spread the procedure without encountering early serious complications. ${ }^{7}$ Herein, the Japanese fenestrated FET option ${ }^{6}$ get part of this simplified approach.

The next question now is, are we really back to the future? Or is the new fenestrated FET a reappraisal of what we already knew? As Emmett "Doc" Brown says in the film Back to the Future, answering to a question from his friend Marty McFly: "The way I see it, if you're gonna build a time machine into a car, why not do it with some style?",

\section{References}

1. Di Bartolomeo R, Pacini D, Savini C, Pilato E, Martin-Suarez S, Di Marco L, et al. Complex thoracic aortic disease: single-stage procedure with the frozen elephant trunk technique. J Thorac Cardiovasc Surg. 2010;140(6 Suppl):S81-5; discussion S86-91. 
2. Pochettino A, Brinkman WT, Moeller P, Szeto WY, Moser W, Cornelius K, et al. Antegrade thoracic stent grafting during repair of acute DeBakey I dissection prevents development of thoracoabdominal aortic aneurysms. Ann Thorac Surg. 2009;88:482-9; discussion 489-90.

3. Tsagakis K, Dohle DS, Wendt D, Wiese W, Benedik J, Lieder H, et al. Left subclavian artery rerouting and selective perfusion management in frozen elephant trunk surgery. Minim Invasive Ther Allied Technol. 2015;24:311-6.

4. Di Marco L, Pantaleo A, Leone A, Murana G, Di Bartolomeo R, Pacini D. The frozen elephant trunk technique: European Association for Cardio-Thoracic Surgery Position and Bologna experience. Korean J Thorac Cardiovasc Surg. 2017;50:1-7.
5. Roselli EE, Idrees JJ, Bakaeen FG, Tong MZ, Soltesz EG, Mick S, et al. Evolution of simplified frozen elephant trunk repair for acute DeBakey Type I dissection: midterm outcomes. Ann Thorac Surg. 2018; 105:749-55.

6. Okamura H, Arakawa M, Takeuchi T, Adachi H. The fenestrated frozen elephant trunk technique for acute type A aortic dissection. J Thorac Cardiovasc Surg. 2018; 156:e75-7.

7. Di Bartolomeo R, Murana G, Di Marco L, Pantaleo A, Alfonsi J, Leone A, et al. Frozen versus conventional elephant trunk technique: application in clinical practice. Eur J Cardiothorac Surg. 2017;51(Suppl 1):i20-8. 